\title{
Knowledge Integration in ISD Project Teams: A Transactive Memory Perspective
}

\author{
Tung-Ching Lin', Kuang-Ting Cheng², Sheng $\mathrm{Wu}^{3^{*}}$ \\ ${ }^{1}$ Department of Information Management, National Sun Yat-sen University, Kaohsiung, Taiwan \\ ${ }^{2}$ Department of Information Management, National United University, Miaoli, Taiwan \\ ${ }^{3}$ Department of Information Management, Southern Taiwan University of Science and Technology, Tainan, \\ Taiwan \\ Email: drtclin@gmail.com, nsysuichiro@gmail.com, $\underline{\text { shengwu@mail.stust.edu.tw }}$
}

Received 27 August 2014; revised 27 September 2014; accepted 18 October 2014

Academic Editor: Grigorios L. Kyriakopoulos, National Technical University of Athens (NTUA), Greece

Copyright (C) 2014 by authors and Scientific Research Publishing Inc.

This work is licensed under the Creative Commons Attribution International License (CC BY).

http://creativecommons.org/licenses/by/4.0/

cc) (i) Open Access

\begin{abstract}
Many organizations frequently establish information system development (ISD) project teams in order to solve specific problems. Knowledge tends to be stored within individuals who are often dispersed over time. However, knowledge integration is required to solve new types of problems. The transactive memory system (TMS) has been suggested as a critical mechanism for facilitating knowledge integration as part of the team's processes. TMS can help the knowledge team to recognize the presence of individuals with diverse knowledge and optimize their value. In this paper, we use TMS and the concept of "collective mind" to explain how the team members' heedful interrelations and mindful comprehension function within the social system. We also discuss in detail how antecedent factors affect TMS. Drawing on data from a study of 339 part-time MBA students who were members of knowledge teams, the findings of this research showed that all our hypotheses were statically significant. Discussions and implications for academics and practitioners are provided.
\end{abstract}

\section{Keywords}

Knowledge Integration, Transactive Memory System, Collective Mind, PLS

\section{Introduction}

Modern organizations are faced with challenges from the external environment in these tough economic times.

*Corresponding author. 
The ability to innovate is essential if a modern organization is to be competitive, because it allows for the successful implementation of creative ideas which bring new products, processes or services [1] [2]. Innovation depends upon knowledge management as its foundation. Many organizations frequently establish information system development (ISD) project teams to solve specific problems. The ISD project team conducts a knowledge-intensive process that includes several knowledge-related activities. Most knowledge sources are individuals who may disperse over time. The team depends on knowledge integration to solve new types of problems. Many studies point out that knowledge integration can enhance a company's capabilities, providing a competitive advantage [3]. This is why knowledge integration is such an important step in knowledge management.

The transactive memory system (TMS) has been suggested as a critical mechanism for facilitating knowledge integration as part of the team's processes [4]. TMS can help a knowledge team recognize the presence of individuals with diverse knowledge and optimize their value [5]. The organization's learning can optimize the value of the process. Organization learning differs from individual learning in that it must consider the influence of the social system. The concept of the "collective mind" has been developed to explain heedful interrelations and mindful comprehension among team members [6].

Successful teamwork relies on the extent to which members can integrate their knowledge and expertise [7] [8], and coordinate and synthesize their actions [9] [10]. Training together, task interdependence, shared experiences, common language and joint decision making facilitate the development of transactive memory among team members [11]-[14].

In this paper, the purpose of our study was to study team knowledge integration processes. To do so, we use TMS and collective mind to explain how the team members' heedful interrelations and mindful comprehension function within the social system. In addition, we explored the mediating role of collective mind between TMS and knowledge integration.

\section{Literature Review and Hypotheses}

\subsection{Knowledge Integration}

If our ability to gain, store and process knowledge is limited, every kind of expert will be required to help us effectively acquire new knowledge [15]. We divide knowledge integration literature into two classifications. The first classification is the definition of knowledge integration. Various authors made suitable explanations regarding knowledge integration between 1992 and 2005. Grant's definition from 1996 is considered the mainstream. Knowledge integration can be defined as the synthesis of existing knowledge and acquired knowledge [16]. In his definition of knowledge integration, Grant [17] noted that, from an organizational performance standpoint, the ability to integrate each kind of specialized knowledge is an organization's competitive advantage. Knowledge integration is an activity that strengthens the enterprise's internal culture and promotes working efficiency [18].

Knowledge integration is a link between individuals and the organization [19]. Knowledge reorganization, sharing and proliferation promotes such linking [20] [21]. An ongoing process of collecting specialized knowledge and expertise can create organizational value and increase the effectiveness of knowledge application [7] [18] [22]-[26]. As far as content is concerned, the major challenge is to integrate internal knowledge and acquire outside knowledge [27].

The second classification of knowledge integration literature regards the content. This literature discusses knowledge integration methods and mechanisms. Some literature discusses the methods of knowledge integration in detail. Grant [17] identified three characteristics of knowledge integration: 1) The efficiency of integration: the degree of ability to access and utilize specialized knowledge held by the organization's individual members. Integration efficiency is determined by the degree of coordination and the existence of an organizational structure which can facilitate the sharing of common knowledge existence among the participants; 2) The scope of integration: the breadth of specialized knowledge available to increase the organization's capabilities. The greater the scope of integration, the higher the level of capability; 3) The flexibility of integration: the extent to which the organization is capable of connecting additional knowledge and reconfiguring existing knowledge.

Practically speaking, an organization can generally integrate knowledge on two levels. One level is for the employees to integrate each others' individual knowledge, based on their own knowledge. The second level is to integrate organizational knowledge across departments. Grant [17] also identified four mechanisms for knowledge integration: 1) Rules and directives which are one kind of coordinated action that can help to convert tacit 
knowledge into explicit; 2) Sequencing, in which knowledge integration joins the time factor, allowing specialized knowledge to be used independently; 3) Routines, via which complex interactions within groups and organizations can be sustained without rules; and 4) Group problem-solving and decision-making, since the creation of new designs for solving novel and complex problems relies on interactions.

\subsection{Transactive Memory System}

A team's knowledge integration will provide a competitive advantage for the organization. A team is a group of two or more individuals who must interact cooperatively and adaptively to work on shared objectives [28]. An individual team member's knowledge is limited, and the team cannot depend entirely on some individual expert who stores specific knowledge needed by all teams. Therefore when one individual can't solve the problem using his own knowledge, he must retrieve the required knowledge from other individuals. The term "transactive memory" has its origins in the concept of external storage acting as an extension of individual memory.

Transactive memory develops when individuals use the memories of other individuals as external storage [29]. Wegner pointed that transactive memory is a shared system for encoding, storing, and retrieving knowledge. There are three components of transactive memory: 1) Directory creation-the process whereby members of the group come to learn where knowledge is likely to be stored amongst group members (the easy definition is "who knows what"); 2) Information allocation-the process of distributing knowledge to the members whose expertise is best suited for its storage; and 3) Knowledge retrieval — the effective disbursal of expertise within the group [29].

We divide the transactive memory theory literature into three classifications. The first is the study of the content of TMS. TMS is intended to expand the theory of transactive memory to the group level. Lewis [5] described the three components of TMS as: 1) Specialization - the knowledge structure which may be differentiated between various members; 2) Credibility - the degree of accuracy and reliability of other members' knowledge; and 3) Coordination - the process of knowledge transmission [30]. Hollingshead [31] proposed a different view, suggesting that the two components of TMS are task experience and member. Kanawattanachai and Yoo [32] used three components to develop a TMS survey questionnaire: expertise location, cognitionbased trust and task-knowledge coordination.

The second classification of TMS literature concerns independent variables. A lot of literature can be found regarding the impact factors of TMS. The impact factors may be divided into four kinds. The first factor of the independent variables is the relationships between team members. This includes common experience and social capital as proposed by Wegner [33] and Hollingshead [31]. Hollingshead [11] also thought that shared experiences, common language, and joint decision making can develop the transactive memory. This portion of the literature also considers the concepts of stability, interpersonal trust, team member proximity, team member familiarity proposed by Akgün [34]. The second factor of the independent variables is training which is mentioned by many researchers. The third factor of the independent variables is communication. According to the literature, the method and frequency of communication can affect TMS. The fourth factor of the independent variables is the characteristics of the team. This includes the number of team members, the stress level, time constraints and the characteristics of individual team members. Taking into account all the impact factors considered by the literature, we believed that training, interdependence, shared experiences, common language, joint decision making and communication were the most important.

The third classification of TMS literature concerns dependent variables which are divided into three kinds when viewed in detail. The first factor of the dependent variables is the performance and stability of the team. Prior studies have consistently suggested that TMS can affect team project outcomes [34]-[37]. Prior studies have also suggested consistently that TMS can enhance team performance [32] [38]-[40]. The second factor of the dependent variables is knowledge management as proposed by Hollingshead [31], Alavi and Tiwana [22] and Griffith, Sawyer [12]. Prior studies have consistently suggested that TMS can help a group to develop knowledge management [12] [22] [31]. The third factor of the dependent variables is organization memory. The literature states that TMS can help organizations to develop the memory of the organization. TMS can also facilitate information searches within a social network [41]. The above TMS literature suggests that TMS theory is still in the early stages of development. Some authors use TMS to study team performance, but there are few studies regarding the use of it in knowledge management. We thought TMS could explain a team's knowledge integration. 
Knowledge integration can be defined as the synthesis of existing knowledge and acquired knowledge [16]. Grant [17] noted that the integration of specialized knowledge is an organization's competitive advantage. TMS has been suggested as a critical mechanism for facilitating knowledge integration within the team's processes. TMS can help a knowledge team recognize the presence of individuals with diverse knowledge and optimize their value [5]. As per the above literature discussion, TMS can help a team find its knowledge. A solid TMS can ensure knowledge integration will be well developed. Therefore, we hypothesise that:

Hypothesis 1: The TMS will be positively related to the development of knowledge integration.

\subsection{Collective Mind}

An individual placed in a new environment undergoes a transformational process of social integration, creating new behaviors. These behaviors will then produce a new environmental structure and a new social culture which form a collective atmosphere. This is the collective mind concept proposed by Weick and Roberts [6]. Collective mind is defined as a process which contains a pattern of heedful interrelations of actions within a social system [6]. This process is usually found in the heedful interrelation of members of a team. Collective mind is made up of three components: contribution, representation and subordination. Contribution refers to actions that are constructed and taken by actors within the system. Representation indicates the actors' understanding that the system is composed of connected actions taken by themselves and others. Subordination reflects the interrelation of actions taken by the actors within the system. Collective mind explains the functions of these interrelationships within the social system, in depth. Therefore, collective mind can help members understand the knowledge of other members. A team can increase its performance by facilitating the collective mind.

Collective mind is defined as the way in which individuals heedfully interrelate their actions [6]. Individuals construct their actions while envisaging a social system of joint actions, and they interrelate that constructed action with the system that is envisaged [40]. Such patterns of interrelating knowledge are socially embedded and emerge over time through repeated interactions and communications among individuals [42] [43]. These emerging patterns in socially shared distributed cognitive systems are influenced by the initial condition of the system and the manner in which individual members interact with each other [44]. The collective mind represents a more advanced form of socio-cognitive systems [40]. Akgün, Byrne [36] used TMS and collective mind to study new development teams. Their research result found that collective mind has a mediating role between TMS and performance. Therefore, we hypothesise that:

Hypothesis 2: The collective mind mediates the relationship between the TMS and knowledge integration.

Training is defined as experts explaining the application to novice users in classroom settings, demonstrating how to use its technical features, observing the learners practicing, and providing feedback [45]. Training provides an important source of knowledge for novices, and is an important organizational intervention contributing to implementation success [46]. Training is an important enabler in the development of TMS [47]. Training facilitates communication and improves the accuracy and effectiveness of TMS [48]. Consistent with these processes, groups that train together are found to outperform groups whose members are trained separately [47]. The effect of training on TMS has typically been demonstrated among coworkers and workgroups in laboratory settings [48]-[50]. Argote [51] indicates that training is a modifier of TMS. Wegner [29] and Brandon and Hollingshead [48] agreed that the combination of team members' training time and training method, indeed, will influence the team's TMS: when team members all participate in the training, the team's transactive memory is improved. As per the above literature discussion, training has a strong effect on TMS. When the team members train together, the team's TMS will be good. Therefore, we hypothesise that:

Hypothesis 3: Training will be positively related to the TMS.

Task interdependence is defined as the degree to which the work between team members is interdependent. Task interdependence is an important prerequisite for stimulating the development of TMS [48] [49]. Task interdependence supports the development of TMS and shared mental models, even in the absence of rich interaction and explicit coordination [52]. Brandon and Hollingshead [48] indicated that the degree of task interdependence among team members is one of the elements that influence transactive memory transfer. As per the above literature discussion, task interdependence is considered essential for the development of TMS. When the team members' tasks are interdependent, the team's TMS will be good. Therefore, we hypothesise that:

Hypothesis 4: Task interdependence will be positively related to the TMS.

Group members rely on each other to take responsibility for storing information, stimulating the development of TMS. These conditions enable rich interaction and information sharing, both of which are considered impor- 
tant for the development of TMS [48]. Brandon and Hollingshead [48] showed that team interdependence is another element that influences transactive memory. Team interdependence can be further divided into common language, shared experience and joint decision making. Common language allows individuals to share and integrate their diverse knowledge. The more established the common language, the more effectively the knowledge will be integrated. When the members are unfamiliar with each others' knowledge, they must use various communication methods to integrate that knowledge. Those methods could include language (and other forms of symbolic communication systems), commonality of professional knowledge, shared meaning and the acknowledgement of personal expertise. Shared experience means that team members communicate with each other to share their personal experience and knowledge. Joint decision making means that when facing a task, the team decides by consensus rather than having a single individual make the final decision. As per the above literature discussion, shared experience, common language, and joint decision making are considered essential for the development of TMS. When the team members have shared experience, common language, and joint decision making, the team's TMS will be good. Therefore, we hypothesise that:

Hypothesis 5: Shared experience will be positively related to the TMS.

Hypothesis 6: Common language will be positively related to the TMS.

Hypothesis 7: Joint decision making will be positively related to the TMS.

Considering the findings in the literature review, this paper therefore proposes the research model shown in Figure 1. As shown in the model, this study attempts to contribute to the TMS research stream by applying TMS to the area of knowledge management.

\section{Research Methodology}

\subsection{Subjects}

Respondents were primarily team members who had been on a team for at least six months. We used snowballing of the sampling to find the appropriate respondents. First, we selected students from a university located in southern Taiwan who were enrolled in the part-time MBA program (concentrating on Management Information Systems) and who were also members of a team. Second, we asked these MBA students to recommend colleagues who also were team members. Finally, a total of 342 respondents participated in the study. The exclusion of incomplete questionnaires resulted in a total of 339 usable responses. Gender distribution was as follows: 62.5 percent $(n=212)$ were male and 37.5 percent $(n=127)$ were female. Education levels were as follows: 8.3 percent $(n=28)$ were high school graduates, 69.3 percent $(n=235)$ were university graduates and 22.4 percent $(n=76)$ held graduate school degrees.

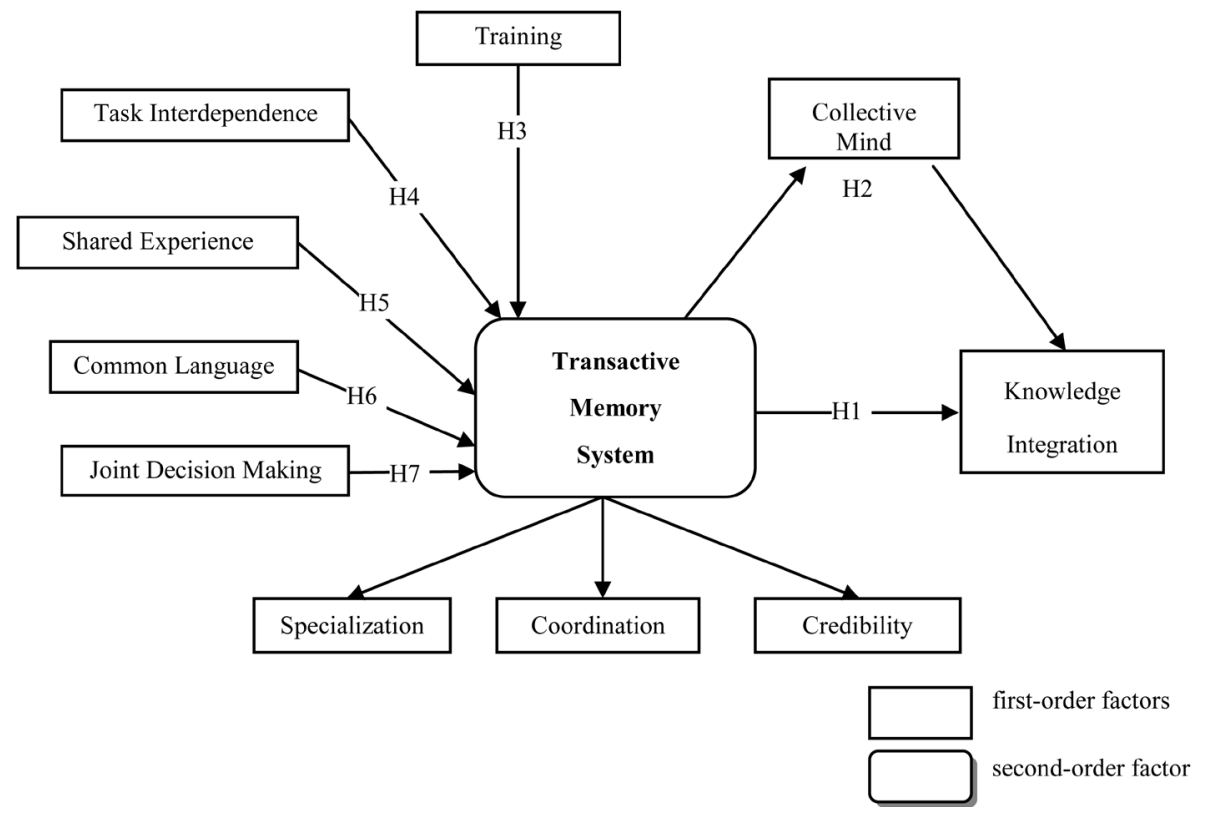

Figure 1. Research model. 


\subsection{Measurement Development}

Constructs were measured using a multiple-item scale drawn from pre-validated studies and reworded to relate specifically to team use. The applicability of the modified items was enhanced by literature reviews, using three MIS professors as expert judges, and pretested using five MBA students working in the industry. During this process, scale items were trimmed and refined, and dimensions were modified to maintain the content validity as our understanding of the constructs improved. All items used five-point Likert scales anchored from "strongly disagree (=1)" to "strongly agree (=5)". Table 1 shows the operational definitions and sources of measurement of variables.

\subsection{Reliability and Validity}

Table 2 demonstrates that almost all the Cronbach's $\alpha$ values fall between $0.793-0.950$, which is in line with the threshold ( $\alpha$ should be $\geq 0.7$ ) proposed by Nunnally [58]. Based on the reliability analysis result, we can sensibly judge our questionnaire set as having an acceptable level of reliability. Discriminant validity is shown by the PLS indicators when the square root of each factor's average variance extracted (AVE) is larger than its correlations with other factors. AVE value will reflect the variance captured by the indicators [59]. In Table 2, seven of our research construct's AVE values were above 0.5 that the square root of each construct's AVE is larger than its correlations with other factors.

Three criteria are used to test convergent validity: loading must above 0.5 , composite reliability (CR) scores must above 0.7, and AVE must above 0.5 [59]. Table 2 demonstrates that all constructs' composite reliability scores are larger than 0.8 , and AVE values are greater than 0.5 . Based on the convergent validity result, we can sensibly judge our research construct set as having an acceptable level of convergent validity.

\subsection{Second-Order of TMS}

We modeled TMS as a second-order construct. Our conceptualization of TMS follows Lewis [5] so it includes three sub-dimensions: specialization, credibility and coordination. Following the guidelines provided by Jarvis [60], we modeled TMS as a second-order formative construct. In measurement model analysis, Smart PLS can produce weight and loadings simultaneously. In general, weight can explain formative indicators [61]. Table 3 reports the formative indicator results. "t value" can test the convenience of the indicator. The results show that specialization, credibility and coordination can strongly explain TMS.

\begin{tabular}{|c|c|c|c|}
\hline Construct & Operational definition & \# of items & References \\
\hline Training & The degree to which members of the team trained together. & 4 & Argote [51] \\
\hline Task interdependence & The degree to which team members' tasks were interdependent. & 4 & Jarvenpaa and Staples [53] \\
\hline Shared experience & The degree of shared experience between the team members. & 5 & Brandon and Hollingshead [48] \\
\hline Common language & The degree of common language between the team members. & 3 & $\begin{array}{l}\text { Brandon and Hollingshead [48], } \\
\text { Chiu [54] }\end{array}$ \\
\hline Joint decision making & The degree of joint decision making amongst the team members. & 5 & $\begin{array}{l}\text { Subramani and Venkatraman [55]; } \\
\text { Zaheer and Venkatraman [56] }\end{array}$ \\
\hline $\begin{array}{l}\text { Transactive } \\
\text { memory system }\end{array}$ & $\begin{array}{l}\text { Specialization is defined as the member's knowledge } \\
\text { which is distinctly different from other members. } \\
\text { Credibility is defined as the member's knowledge } \\
\text { which is correct and may be trusted by another person. } \\
\text { Coordination is defined as members having a } \\
\text { good understanding of who has what knowledge } \\
\text { and how that knowledge fits together. }\end{array}$ & 15 & Lewis [5] \\
\hline Collective mind & Individuals heedfully interrelate their actions. & 4 & Weick and Roberts [6] \\
\hline $\begin{array}{l}\text { Knowledge } \\
\text { integration }\end{array}$ & The synthesis of existing knowledge and acquired knowledge. & 4 & $\begin{array}{l}\text { Kogut and Zander [16], } \\
\text { Tiwana and McLean [57] }\end{array}$ \\
\hline
\end{tabular}


Table 2. Construct correlations and reliability estimates.

\begin{tabular}{cccccccc}
\hline Variables & CM & CL & JDM & KI & SE & TI & TR \\
Common language (CL) & 0.360 & & & & & & \\
Joint decision making (JDM) & 0.392 & 0.586 & & & & & \\
Knowledge integration (KI) & 0.414 & 0.479 & 0.453 & & & & \\
Shared experience (SE) & 0.488 & 0.414 & 0.382 & 0.322 & & & \\
Task interdependence (TI) & 0.442 & 0.517 & 0.377 & 0.500 & 0.408 & & \\
Training (TR) & 0.224 & 0.372 & 0.339 & 0.380 & 0.095 & 0.269 & 0.950 \\
Cronbach's $\alpha$ & 0.835 & 0.853 & 0.868 & 0.860 & 0.904 & 0.873 & 0.73 \\
AVE & 0.669 & 0.772 & 0.650 & 0.703 & 0.724 & 0.724 & 0.871 \\
CR & 0.890 & 0.910 & 0.902 & 0.904 & 0.929 & 0.913 & 0.964 \\
\hline
\end{tabular}

Note: CM: Collective mind.

Table 3. The weight and t-value of formative indicators.

\begin{tabular}{cccc}
\hline Latent variable & Indicators & Weight & t-value \\
\hline \multirow{2}{*}{ TMS } & Specialization & 0.564 & $16.375^{* * *}$ \\
& Credibility & 0.709 & $21.925^{* * *}$ \\
& Coordination & 0.549 & $15.248^{* * *}$ \\
\hline
\end{tabular}

Note: ${ }^{* * *} \mathrm{p}<0.001$.

\section{Results}

In this paper, we assessed the hypotheses by using structural equation modeling because of its ability to validate multiple causal relationships simultaneously. Smart PLS 2.0 M3 with bootstrapping as a resampling technique (500 random samples) was used to estimate the structural model and the significance of the paths (Chin, 1998). Figure 2 shows the structural model. The research findings show that all the hypotheses were statically significant.

$\mathrm{H} 4$, hypothesizing that task interdependence positively relates to the TMS, is strongly supported $(\beta=0.236)$. $\mathrm{H} 5$, hypothesizing that shared experience positively relates to the TMS, is well supported $(\beta=0.170)$. H6, hypothesizing that common language positively relates to the TMS, is strongly supported $(\beta=0.225)$. H7, hypothesizing that joint decision making positively relates to the TMS, is well supported $(\beta=0.150)$. The $R^{2}$ of TMS for the main effect model was $R^{2}=0.394$. H1, hypothesizing that TMS positively relates to knowledge integration, is strongly supported $(\beta=0.517)$. The $R^{2}$ of knowledge integration for the main effect model was $R^{2}=$ 0.267 . The explanatory power is considerably greater than the recommended level of $10 \%$ [62] [63].

To test the mediating role of collective mind, we added the construct of collective mind to the research model, see Figure 3. The results indicated that collective mind is a mediating variable between TMS and knowledge integration. Thus, $\mathrm{H}_{2}$ is supported. To add the mediating role of collective mind, the value of the effect of TMS on knowledge integration is reduced to $(\beta=0.217)$ from $(\beta=0.517)$. This shows a partial mediating effect [64].

\section{Discussion and Conclusions}

In total, the study tested 7 hypotheses, all of which were supported by the data. Testing implications and temporary explanations for unsupported results are explored in this section. In Table 4, the result indicated that training was a significant predictor of the specialization and coordination of TMS, but not a significant predictor of the credibility of TMS. The possible explanation is that training can help team members promote specialized abilities, but can't help members believe in the knowledge supplied by other team members. Each person's individual mind causes him or her to believe other people's knowledge. Training cannot be depended upon to change each person's individual mind. 


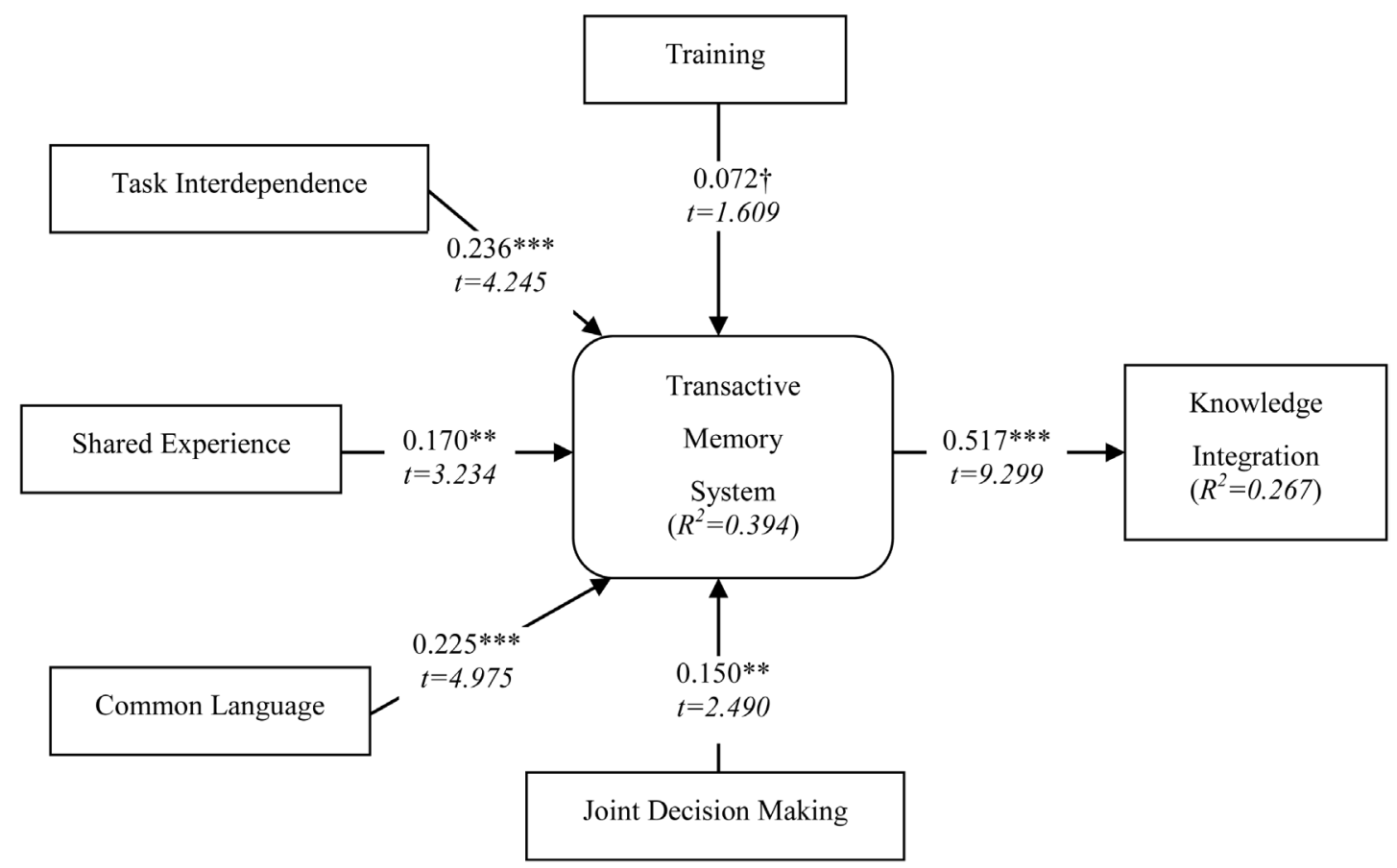

Figure 2. Results of PLS analysis. Notes: The significance of the path estimates was calculated using a bootstrap technique with 500 resamples. ${ }^{\dagger} \mathrm{p}<0.1,{ }^{*} \mathrm{p}<0.05,{ }^{* *} \mathrm{p}<0.01,{ }^{* * *} \mathrm{p}<0.001$ (two-tailed).

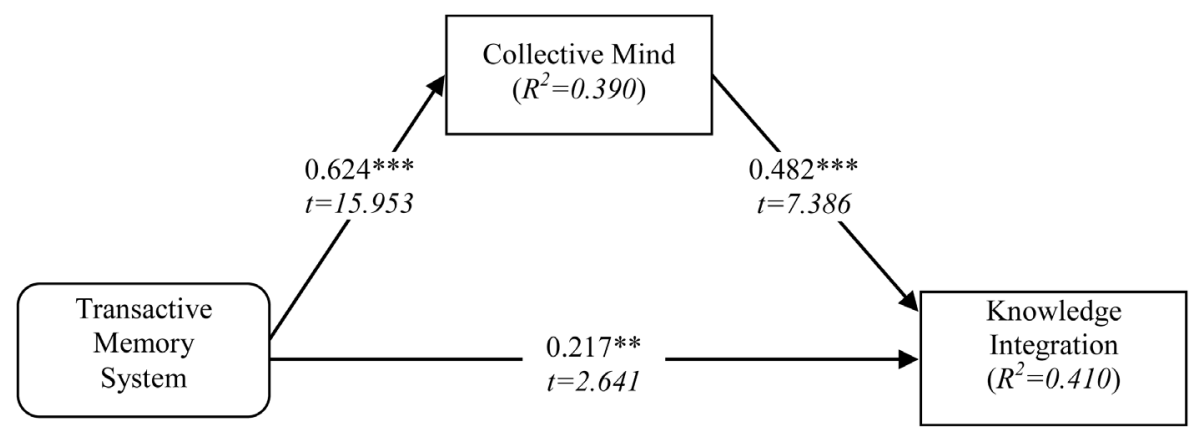

Figure 3. Results of the mediated model. Notes: The significance of the path estimates was calculated using a bootstrap technique with 500 resamples. ${ }^{*} \mathrm{p}<0.05,{ }^{* *} \mathrm{p}<0.01,{ }^{* * *} \mathrm{p}<0.001$ (two-tailed).

Table 4. The results of the TMS analysis.

\begin{tabular}{|c|c|c|c|}
\hline Independent variables & TMS—specialization & TMS—credibility & TMS—coordination \\
\hline Training & $-0.108^{*}$ & 0.043 & $0.249^{* * *}$ \\
\hline Task interdependence & $0.220^{* * * *}$ & $0.256^{* * *}$ & 0.059 \\
\hline Shared experience & $0.072^{\dagger}$ & $0.175^{* *}$ & $0.142^{*}$ \\
\hline Common language & $0.203^{* * *}$ & $0.201^{* * *}$ & $0.128^{*}$ \\
\hline Joint decision making & $0.218^{* * *}$ & 0.037 & $0.132^{*}$ \\
\hline$R^{2}$ & 0.273 & 0.286 & 0.259 \\
\hline
\end{tabular}

Note: ${ }^{\dagger} \mathrm{p}<0.1,{ }^{*} \mathrm{p}<0.05,{ }^{* *} \mathrm{p}<0.01,{ }^{* * *} \mathrm{p}<0.001$. 
The result indicated that task interdependence was a significant predictor of the specialization and credibility of TMS, but not a significant predictor of the coordination of TMS. The possible explanation is that task interdependence is the degree of interdependence between the tasks, which is different from team interdependence. Task interdependence cannot help to promote coordination between team members.

The result indicated that joint decision making was a significant predictor of the specialization and coordination of TMS, but not a significant predictor of the credibility of TMS. The possible explanation is that joint decision making can help team members promote specialized abilities, but it cannot help them to believe in the knowledge supplied by other team members. Each person's individual mind causes him or her to believe other people's knowledge. Joint decision making cannot be depended upon to change each person's individual mind. In our study, we found that common language and shared experience were significant predictors of the specialization, credibility and coordination of TMS. This finding tells us that common language and shared experience are the important factors affecting TMS. The possible explanation is that common language can help team members smoothly obtain the knowledge they want. Shared experience can help team members to understand the knowledge.

However, our study also found the important mediator between the process of TMS and knowledge integration. Knowledge integration must be accomplished through the team's TMS and requires nearly continuous operational reliability. These heedful interrelations of actions in a social system were the collective mind. The result indicated that collective mind was a mediator which contributes part of the mediating effect.

This study has the following academic implications. First, we used TMS to build a knowledge integration model, and other researchers can follow this model to do related research. Second, we found some factors affecting TMS. This finding can enrich TMS domain research. Finally, we confirmed the importance of TMS to a team's knowledge integration. For practitioners, this research results in an empirical work that can help management level staff better understand the process of knowledge integration. A Knowledge Management System (KMS) also provides a function which allows members to share experiences, but it must also ensure that the knowledge is available in a common language. Management can request that members use KMS for joint decision making. Knowledge integration depends on IT, but it also can be achieved by training together. Team members can understand each other better when the team trains together.

\section{Acknowledgements}

Authors are thankful to the National Science Council under the Grants NSC 98-2410-H-218-012-MY2 and NSC 100-2410-H-218-005 for financial support to this research.

\section{References}

[1] Amabile, T.M., Conti, R., Coon, H., Lazenby, J. and Herron, M. (1996) Assessing the Work Environment for Creativity. Academy of Management Journal, 39, 1154-1184. http://dx.doi.org/10.2307/256995

[2] Luecke, R. and Katz, R. (2003) Managing Creativity and Innovation. Harvard Business School Press, Boston.

[3] Van den Bosch, F.A.J. and Van Wijk, R. (2001) Creation of Managerial Capabilities through Managerial Knowledge Integration: A Competence-Based Perspectives. In: Sanchez, R., Ed., Knowledge Management and Organizational Competence, Oxford University Press, Oxford, 159-176.

[4] Lewis, K. (2004) Knowledge and Performance in Knowledge-Worker Teams: A Longitudinal Study of Transactive Memory Systems. Management Science, 50, 1519-1533. http://dx.doi.org/10.1287/mnsc.1040.0257

[5] Lewis, K. (2003) Measuring Transactive Memory Systems in the Field: Scale Development and Validation. Journal of Applied Psychology, 88, 587-603. http://dx.doi.org/10.1037/0021-9010.88.4.587

[6] Weick, K.E. and Roberts, K.H. (1993) Collective Mind in Organizations: Heedful Interrelating on Flight Decks. Administrative Science Quarterly, 38, 357-381. http://dx.doi.org/10.2307/2393372

[7] Newell, S., Tansley, C. and Huang, J. (2004) Social Capital and Knowledge Integration in an ERP Project Team: The Importance of Bridging and Bonding. British Journal of Management, 15, 43-57. http://dx.doi.org/10.1111/j.1467-8551.2004.00405.x

[8] Newell, S., Swan, J. and Galliers, R.D. (2000) A Knowledge-Focused Perspective on the Diffusion and Adoption of Complex Information Technologies: The BPR Example. Information Systems Journal, 10, 239-259. http://dx.doi.org/10.1046/j.1365-2575.2000.00079.x

[9] Nidumolu, S.R. (1996) A Comparison of the Structural Contingency and Risk-Based Perspectives on Coordination in Software-Development Projects. Journal of Management Information Systems, 13, 77-113. 
[10] Yoo, Y., Lyytinen, K. and Heo, D. (2007) Closing the Gap: Towards a Process Model of Post-Merger Knowledge Sharing. Information Systems Journal, 17, 321-347. http://dx.doi.org/10.1111/j.1365-2575.2007.00248.x

[11] Hollingshead, A.B. (1998) Retrieval Processes in Transactive Memory Systems. Journal of Personality and Social Psychology, 74, 659-671. http://dx.doi.org/10.1037/0022-3514.74.3.659

[12] Griffith, T.L., Sawyer, J.E. and Neale, M.A. (2003) Virtualness and Knowledge in Teams: Managing the Love Triangle of Organizations, Individuals, and Information Technology. MIS Quarterly, 27, 265-287.

[13] Highsmith, J. and Cockburn, A. (2001) Agile Software Development: The People Factor. IEEE Computer, 34, 131133.

[14] Staples, D.S. and Webster, J. (2008) Exploring the Effects of Trust, Task Interdependence and Virtualness on Knowledge Sharing in Teams. Information Systems Journal, 18, 617-640. http://dx.doi.org/10.1111/j.1365-2575.2007.00244.x

[15] Simon, H.A. (1979) Information Processing Models of Cognition. Annual Review of Psychology, 30, 363-396. http://dx.doi.org/10.1146/annurev.ps.30.020179.002051

[16] Kogut, B. and Zander, U. (1992) Knowledge of the Firm, Combinative Capabilities, and the Replication of Technology. Organization Science, 3, 383-397. http://dx.doi.org/10.1287/orsc.3.3.383

[17] Grant, R.M. (1996) Toward a Knowledge-Based Theory of the Firm. Strategic Management Journal, 17, 109-122. http://dx.doi.org/10.1002/smj.4250171110

[18] De Boer, M., Van Den Bosch, F.A.J. and Volberda, H.W. (1999) Managing Organizational Knowledge Integration in the Emerging Multimedia Complex. Journal of Management Studies, 36, 379-398. http://dx.doi.org/10.1111/1467-6486.00141

[19] Inkpen, A.C. (1998) Learning, Knowledge Acquisition, Strategic Alliances. European Management Journal, 16, 223229. http://dx.doi.org/10.1016/S0263-2373(97)00090-X

[20] Balasubramanian, P., Nochur, K., Henderson, J.C. and Kwan, M.M. (1999) Managing Process Knowledge for Decision Support. Decision Support Systems, 27, 145-162. http://dx.doi.org/10.1016/S0167-9236(99)00041-X

[21] Zack, M.H. (1999) Managing Codified Knowledge. Sloan Management Review, 40, 45-58.

[22] Alavi, M. and Tiwana, A. (2002) Knowledge Integration in Virtual Teams: The Potential Role of KMS. Journal of the American Society for Information Science \& Technology, 53, 1029-1037. http://dx.doi.org/10.1002/asi.10107

[23] Davenport, T.H. and Glaser, J. (2002) Just-in-Time Delivery Comes to Knowledge Management. Harvard Business Review, 80, 107-111.

[24] Huang, J.C. and Newell, S. (2003) Knowledge Integration Processes and Dynamics within the Context of Cross-Functional Projects. International Journal of Project Management, 21, 167-176. http://dx.doi.org/10.1016/S0263-7863(02)00091-1

[25] Neumann, E. and Thomas, J. (2002) Knowledge Assembly for the Life Sciences. Drug Discovery Today, 7, S160-S162. http://dx.doi.org/10.1016/S1359-6446(02)02432-7

[26] Robbins, S. and Coulter, M. (2005) Management. Pearson Prentice, Upper Saddle River.

[27] Shin, M., Holden, T. and Schmidt, R.A. (2001) From Knowledge Theory to Management Practice: Towards and Integrated Approach. Information Processing and Management, 37, 335-355. http://dx.doi.org/10.1016/S0306-4573(00)00031-5

[28] Cannon-Bowers, J.A., Salas, E. and Converse, S.A. (1993) Shared Mental Models in Expert Team Decision-Making. In: Castellan Jr., N.J., Ed., Individual and Group Decision Making, Lawrence Erlbaum, Hillsdale, 221-246.

[29] Wegner, D.M. (1995) A Computer Network Model of Human Transactive Memory. Social Cognition, 13, $319-339$. http://dx.doi.org/10.1521/soco.1995.13.3.319

[30] Moreland, R.L. (1999) Transactive Memory: Learning Who Knows What in Word Groups and Organizations. In: Thompson, L.L., Levine, J.M. and Messick, D.M., Eds., Shared Cognition in Organizations: The Management of Knowledge, Lawrence Erlbaum Associates, Mahwah, 3-31.

[31] Hollingshead, A.B. (2000) Perceptions of Expertise and Transactive Memory in Work Relationships. Group Processes \& Intergroup Relations, 3, 257-267. http://dx.doi.org/10.1177/1368430200033002

[32] Kanawattanachai, P. and Yoo, Y. (2007) The Impact of Knowledge Coordination on Virtual Team Performance over Time. MIS Quarterly, 31, 783-808.

[33] Wegner, D.M., Erber, R. and Raymond, P. (1991) Transactive Memory in Close Relationships. Journal of Personality and Social Psychology, 61, 923-929. http://dx.doi.org/10.1037/0022-3514.61.6.923

[34] Akgün, A.E., Byrne, J., Keskin, H., Lynn, G.S. and Imamoglu, S.Z. (2005) Knowledge Networks in New Product Development Projects: A Transactive Memory Perspective. Information \& Management, 42, 1105-1120. 
http://dx.doi.org/10.1016/j.im.2005.01.001

[35] Hsu, J.S.C., Shih, S.P., Chiang, J.C. and Liu, J.Y.C. (2012) The Impact of Transactive Memory Systems on IS Development Teams' Coordination, Communication, and Performance. International Journal of Project Management, 30, 329-340. http://dx.doi.org/10.1016/j.ijproman.2011.08.003

[36] Akgün, A.E., Byrne, J.C., Keskin, H. and Lynn, G.S. (2006) Transactive Memory System in New Product Development Teams. IEEE Transactions on Engineering Management, 53, 95-111. http://dx.doi.org/10.1109/TEM.2005.857570

[37] Lin, T.C., Hsu, J.S.C., Cheng, K.T. and Wu, S. (2012) Understanding the Role of Behavioural Integration in ISD Teams: An Extension of Transactive Memory Systems Concept. Information Systems Journal, 22, 211-234. http://dx.doi.org/10.1111/j.1365-2575.2011.00383.x

[38] Austin, J.R. (2000) Knowing What and Whom Other People Know: Linking Transactive Memory with External Connections in Organizational Groups. Academy of Management Proceedings, 2000, F1-F6.

[39] Rau, D. (2006) Top Management Team Transactive Memory, Information Gathering, and Perceptual Accuracy. Journal of Business Research, 59, 416-424. http://dx.doi.org/10.1016/j.jbusres.2005.07.001

[40] Yoo, Y. and Kanawattanachai, P. (2001) Developments of Transactive Memory Systems and Collective Mind in Virtual Teams. International Journal of Organizational Analysis, 9, 187-208. http://dx.doi.org/10.1108/eb028933

[41] Borgatti, S.P. and Cross, R. (2003) A Relational View of Information Seeking and Learning in Social Networks. Management Science, 49, 432-445. http://dx.doi.org/10.1287/mnsc.49.4.432.14428

[42] Faraj, S. and Sproull, L. (2000) Coordinating Expertise in Software Development Teams. Management Science, 46, 1554-1568. http://dx.doi.org/10.1287/mnsc.46.12.1554.12072

[43] Tsoukas, H. (1996) The Firm as a Distributed Knowledge System: A Constructionist Approach. Strategic Management Journal, 17, 11-25. http://dx.doi.org/10.1002/smj.4250171104

[44] Hutchins, E. (1996) Cognition in the Wild. MIT Press, Cambridge.

[45] Yi, M.U. and Davis, F.D. (2003) Developing and Validating an Observational Learning Model of Computer Software Training and Skill Acquisition. Information Systems Research, 14, 146-169. http://dx.doi.org/10.1287/isre.14.2.146.16016

[46] Nelson, R.R. and Cheney, P.H. (1987) Training End Users: An Exploratory Study. MIS Quarterly, 11, 547-559. http://dx.doi.org/10.2307/248985

[47] Kane, A.A., Argote, L. and Levine, J.M. (2005) Knowledge Transfer between Groups via Personal Rotation: Effects of Social Identity and Knowledge Quality. Organizational Behavior and Human Decision Processes, 96, 56-71. http://dx.doi.org/10.1016/j.obhdp.2004.09.002

[48] Brandon, D.P. and Hollingshead, A.B. (2004) Transactive Memory Systems in Organizations: Matching Tasks, Expertise, and People. Organization Science, 15, 633-644. http://dx.doi.org/10.1287/orsc.1040.0069

[49] Wegner, D.M. (1986) Transactive Memory: A Contemporary Analysis of the Group Mind. In: Mullen, B. and Goethals, G.R., Eds., Theories of Group Behavior, Springer-Verlag, New York, 185-205.

[50] Wegner, D.M., Giuliano, T. and Hertel, P.T. (1985) Cognitive Interdependence in Close Relationships. In: Ickes, W., Ed., Compatible and Incompatible Relationships, Springer Verlag, New York, 253-276.

[51] Argote, L. (1999) Organizational Learning: Creating, Retaining, and Transferring Knowledge. Springer, Berlin.

[52] Sharma, R. and Yetton, P. (2007) The Contingent Effects of Training, Technical Complexity, and Task Interdependence on Successful Information Systems Implementation. MIS Quarterly, 31, 219-238.

[53] Jarvenpaa, S.L. and Staples, D.S. (2001) Exploring Perceptions of Organizational Ownership of Information and Expertise. Journal of Management Information Systems, 18, 151-183.

[54] Chiu, C.M., Hsu, M.H. and Wang, E.T.G. (2006) Understanding Knowledge Sharing in Virtual Communities: An Integration of Social Capital and Social Cognitive Theories. Decision Support Systems, 42, 1872-1888. http://dx.doi.org/10.1016/j.dss.2006.04.001

[55] Subramani, M.R. and Venkatraman, N. (2003) Safeguarding Investments in Asymmetric Interorganizational Relationships: Theory and Evidence. Academy of Management Journal, 46, 46-62. http://dx.doi.org/10.2307/30040675

[56] Zaheer, A. and Venkatraman, N. (1995) Relational Governance as an Interorganizational Strategy: An Empirical Test of the Role of Trust in Economic Exchange. Strategic Management Journal, 16, 373-392. http://dx.doi.org/10.1002/smj.4250160504

[57] Tiwana, A. and McLean, E.R. (2005) Expertise Integration and Creativity in Information Systems Development. Journal of Management Information Systems, 22, 13-43.

[58] Nunnally, J.C. (1978) Psychometric Theory. McGraw-Hill, New York. 
[59] Fornell, C. and Larcker, D.F. (1981) Evaluating Structural Equation Models with Unobservable Variables and Measurement Error. Journal of Marketing Research, 18, 39-50. http://dx.doi.org/10.2307/3151312

[60] Jarvis, C.B., MacKenzie, S.B. and Podsakoff, P.M. (2003) A Critical Review of Construct Indicators and Measurement Model Misspecification in Marketing and Consumer Research. Journal of Consumer Research, 30, 199-218. http://dx.doi.org/10.1086/376806

[61] Chin, W.W. (1998) Commentary: Issues and Opinion on Structural Equation Modeling. MIS Quarterly, 22, 7-16.

[62] Phang, C.W., Sutanto, J., Kankanhalli, A., Li, Y., Tan, B.C.Y. and Teo, H.H. (2006) Senior Citizens’ Acceptance of Information Systems: A Study in the Context of e-Government Services. IEEE Transactions on Engineering Management, 53, 555-569. http://dx.doi.org/10.1109/TEM.2006.883710

[63] Falk, R.F. and Miller, N.B. (1992) A Primer for Soft Modeling. University of Akron Press, Akron.

[64] Baron, R.M. and Kenny, D.A. (1986) The Moderator-Mediator Variable Distinction in Social Psychological Research: Conceptual, Strategic, and Statistical Considerations. Journal of Personality and Social Psychology, 51, 1173-1182. http://dx.doi.org/10.1037/0022-3514.51.6.1173 
Scientific Research Publishing (SCIRP) is one of the largest Open Access journal publishers. It is currently publishing more than 200 open access, online, peer-reviewed journals covering a wide range of academic disciplines. SCIRP serves the worldwide academic communities and contributes to the progress and application of science with its publication.

Other selected journals from SCIRP are listed as below. Submit your manuscript to us via either submit@scirp.org or Online Submission Portal.
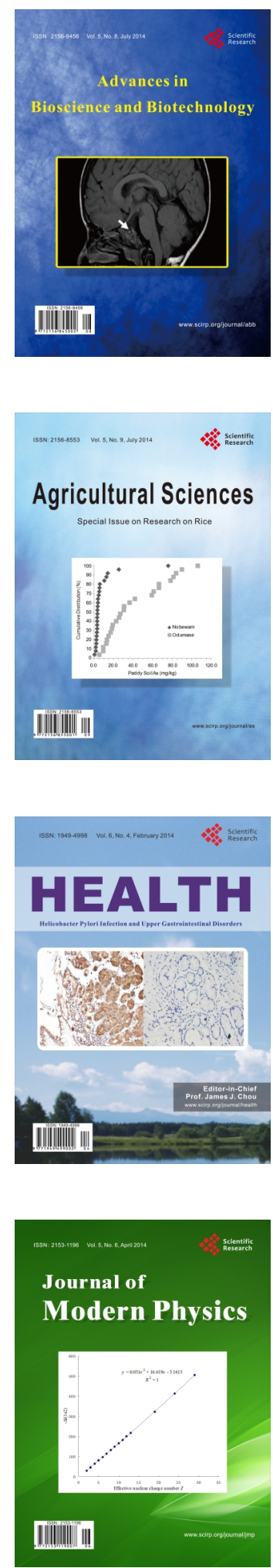
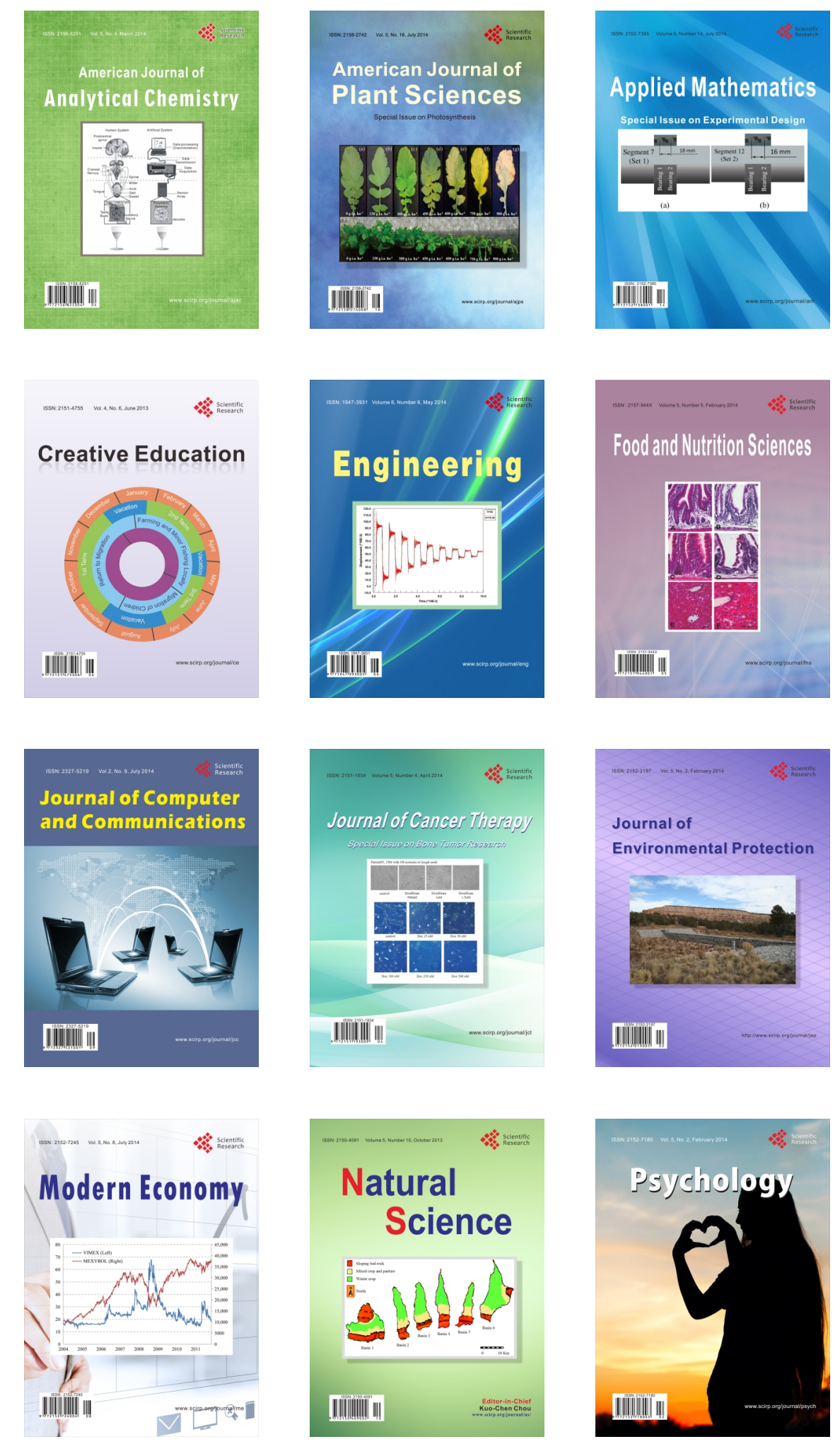